\title{
Cuban Medical Internationalism through a Feminist Perspective
}

\author{
José 0 . Pérez* \\ André L. Reis da Silva**
}

\begin{abstract}
This article analyses Cuban medical internationalism through a feminist International Relations lens. Our results are based on numerous in-depth semi-structured interviews and fieldwork conducted with both female and male participants in these programmes. The doctors we interviewed have concluded medical missions in countries such as Brazil, Venezuela, Angola and Ghana. We argue that examining Cuban medical internationalism from a feminist IR perspective gives us insights into the nuanced status of feminism within Cuban civil society, how international employment impacts family relations both positively and negatively, and how time spent abroad provides transformative experiences. This paper seeks to contribute to greater conversations on power, agency and gender in the global South.
\end{abstract}

Keywords: Cuban medical internationalism; feminist theory; global South; power; international relations.

Since coming to power in 1959 , the Cuban revolutionary government set out to create an impressive domestic health care system with tremendous results in terms of public health indicators. Life expectancy in Cuba is currently about 77 years for men and 81 for women, which is considerably higher than in other developing countries (UN 2016: 90). Childhood mortality in Cuba is around 4.3 deaths per 1000 births, which is lower than in the USA, around 6 per 1000 births (UN 2016: 436-7). Cuba also has a surplus of doctors, considering it has more doctors than Canada, which has a population three times that of the Caribbean island country (Kirk, Kirk and Walker 2015: 5). Internationally, Cuba has translated its comparative advantage in the medical field into soft power and economic gains by carrying out countless disaster relief operations as well as long-term medical missions throughout the global South (Bustamante and Sweig 2008). In 2016, for example, the Caribbean country earned about $\$ 8.2 \mathrm{~b}$ from its 25000 doctors and 30000 nurses and other medical professionals working abroad in 67 countries, with $\$ 500 \mathrm{~m}$ from Brazil alone (Waters 2017).

\footnotetext{
* Federal University of Rio Grande do Sul (UFRGS), Porto Alegre-RS, Brazil; jose.oviedo.perez@gmail.com. ORCID iD 0000-0002-9302-4591.

** Federal University of Rio Grande do Sul (UFRGS), Porto Alegre-RS, Brazil; reisdasilva@hotmail.com. ORCID iD 0000-0003-2593-1189.
} 
Cuban medical internationalism, as these exchanges are typically called, is not new, and the academic literature is rife with in-depth studies of these programmes and how they affect public health indicators (Feinsilver 2008; Kirk and Erisman 2009; Brouwer 2011; Kirk, Kirk and Walker 2015). In this research article we hope to make feminist sense (Enloe 2014: 3) of contemporary Cuban medical internationalism. Approaching this Cuban foreign policy tool from a feminist perspective is crucial because $61.7 \%$ of doctors and $70.8 \%$ of healthcare workers in Cuba are women; and the majority of the participants in these foreign medical programs are also women (MINSAP 2016: 120, 1234). Specifically, we depart from the research question: what insights about international politics can be gained by employing a feminist International Relations (IR) perspective to analyse Cuban medical internationalism? In the following sections we present our theoretical basis in more detail and describe our methodological procedures. For this research study, we conducted in-depth semi-structured interviews to achieve a critical and interpretive research study based on qualitative data. We argue that examining Cuban medical internationalism from a feminist IR perspective furthers our understanding of the nuanced status of feminism within Cuban civil society, how internationalisation affects family relations both positively and negatively, and how these programmes present opportunities for transformative experiences and agency. Through the discussions advanced here, we seek to expand pre-existing feminist IR literature by arguing that women - especially women from the global South - are not a monolithic entity with parallel needs and experiences, and problematise our understanding of the role of women within Cuban society and foreign policy.

\section{Literature review}

Since the introduction of feminist perspectives to IR in the 1980s, many advances have been made towards demonstrating that women and gender perspectives provide needed insights for security studies, international economics and our understanding of the international system (Ticker 1992, 2001; Enloe 1993, 2014; Ackerly 2000; Gentry and Sjoberg 2015). Specifically, feminists have challenged IR's traditional focus on interstate politics (Tickner 2001: 2) and the binaries it creates around gender (Tickner 1992: 7). Instead of looking at domestic/feminine and international/masculine spheres, feminist IR scholars have challenged western metaphysics to include dialogues about agency, power, hierarchies and other processes that traverse the international system. Third World scholars have also critiqued feminist perspectives as being based on the experiences of women from the global North, and much research has been conducted on the intricacies within the margins of IR (Mohanty 1988; Enloe 1996; Chin 1998; Molyneux 2001; Piedalue and Rishi 2017). These scholars have introduced intersectionality and other variables beyond gender to understand the experiences of global South women and not interpret their experiences as a singular story of oppression. This research paper seeks to explore the complexities and nuances of experiences that result when diverse Cuban women and men participate in medical missions and find themselves in new social and political settings. 
Likewise, we will analyse how these doctors exert power and challenge traditional gender roles and family structures. By 'power' this research study follows Foucault's ideas about a nexus between power and knowledge, whereby power is not only oppressive, but also productive (Foucault 2001: 119-120). Put differently, power is multifaceted or, as Barnett and Duvall (2005: 42) define it, 'the production, in and through social relations, of effects that shape the capacities of actors to determine their circumstances and fate.

Many scholars have previously contributed lengthy and detailed works on Cuban medical internationalism (Feinsilver 2008; Kirk and Erisman 2009; Brouwer 2011). These scholars focused on the Marxist ideological foundations to Cuban medical internationalism stemming from Che Guevarra, as well as the resulting legitimacy and soft power it brings to Cuban foreign policy (Feinsilver 1989; Bustamante and Sweig 2008). The first Cuban international medical mission occurred in 1960, when an earthquake devastated Chile (Feinsilver 2010: 87), and this has since evolved into a long-standing tradition of assistance ranging from disaster relief to longer-term missions around the world. Previous scholars focused on how Cuban doctors affect macro-health indicators such as infant mortality, life expectancy and vaccination rates around the world (Kirk 2009). The experiences of the individual doctors, when interviewed, have been limited to reflecting on the medical profession and their contribution to reducing global public health disparities, despite Cuba's shortage of resources. Pre-existing scholarship fails to critically analyse the power relations and experiences of individuals, specifically women, who participate in these programmes.

Women have been present in Cuban medical internationalism from the beginning, as historian Piero Gleijeses reveals through the story of Sara Perelló, one of the first female internacionalistas, who enlisted in a medical mission to Algeria in 1963 (Gleijeses 2002: 34-37). As Blue (2010: 37) presents, the majority of Cuban doctors and participants in these foreign medical missions are women, but academic approaches have often focused on empirical assessments of outcomes. We employ an interpretative approach through semi-structured interviews to critically unpack the experiences of women in these missions. As Enloe (2014: 3) writes, 'Making useful sense - feminist sense - of international politics requires us to follow diverse women to places that are usually dismissed [...] as merely "private," "domestic," "local," or "trivial." The experiences of women, especially women from the global South, have been left on the margins of IR. Here we seek to bring them to the forefront to better understand the international system. But in the same manner that Vrasti (2008: 288-290) criticises Enloe's work, even feminist scholars can fall into the trap of objectifying and neutering their participants' voices when employing interviews in feminist research. This study hopes to avoid that pitfall by not viewing women as a monolithic entity or what Fujii (2010: 236) calls, 'neat, analytic packages.' Instead, we give precedence to the diversity of women's lived experiences and the opportunity to express them in their own words, while simultaneously noting the importance of intersectionality. Secondly, the experiences of women also affect men and vice-versa, which is why feminist research should also analyse the experiences of men, as Baldez (2012: 320) argues. 
Turning more specifically towards Cuban women and society, as historian Michelle Chase (2015: 44, 80) contends, women were present at every stage of the revolution, but were only allowed to participate in the anti-Batista struggle by 'acting' within traditionally feminine roles, such as mother. Or, as Lisa Baldez (2012: 322) phrases it: 'Revolutionary policies challenged the subordinate role of women within Catholic-dominated culture, but did not transform it.' Consequently, women and their contributions to the revolution were largely sidelined, while the contributions of men were highlighted and lionized (Chase 2015), a common occurrence throughout revolutionary processes (Enloe 2014: 108-114). In fact, a common critique of the post-revolutionary Cuban state is that it challenged class and inequality, while at times silencing discourses surrounding gender, race, and sexuality in order to maintain social cohesion (see Fernandes 2003; Sawyer 2006; Baldez 2012; Johnson 2012; Chase 2015). Although Fidel Castro once called women, 'The revolution within the revolution, the Cuban regime after 1959 did not radically alter gender hierarchies and patriarchal norms (Chase 2015). Early advances, such as the Family Code of 1975, which defined household duties and rights between men and women, were soon left on paper as the leadership realised how troublesome and difficult it could be to shift society at its bedrock (Kapcia 2008: 50-51).

However, the agency of Cuban women cannot be totally discounted or ignored. As many scholars have posited, there exists a complex relationship and tension within contemporary Cuban society between individuals and the state, whereby the former have multiple interests and identities that are negotiated in intricate ways against those of the latter (Lutjens 2002: 219-220; Fernandes 2005; Hearn 2008; Gold 2015). Or as Gold (2015: 193) advances, 'the revolution is made by people in their daily practices, not just as political subjects, but as human beings, thoroughly situated in social, cultural, and historical circumstances. Thus, post-Soviet Cuban society is a complex setting where agency manifests itself in unexpected ways and social relations are constantly being (re)examined (Brotherton 2012; Hamilton 2012; Stout 2014; Gordy 2015). This paper seeks to contribute to that conversation by also (re)examining the ways in which social relations are constantly altered through participation in international medical missions. As Blue (2010: 32) writes: 'The fact that Cuba's medical profession is unique in its gender and racial parity means that international missions are providing groups that have been disadvantaged in the dual economy access to the dollar economy and a higher standard of living.' ${ }^{1}$ This claim must be further unpacked and contextualised through qualitative research. Thus, we aim to contribute to the growing academic literature on women's participation and experiences (see Núñez Sarmiento 2005, 2010; Blue 2010; Jerónimo Kersh 2017) in the post-Soviet Cuban workforce, and to better situating those previous findings.

In this section, we have highlighted the epistemology that guides this research project and outlined the contributions we seek to make within scholarly literature on gender in the global South, feminist IR theory and women in Cuban civil society. We utilise an interdisciplinary and interpretative approach to Cuban medical internationalism, which has conventionally been studied from a state-centric or empirical perspective. At the macro-level, this study should further discussions on the functioning of international politics, 
and what happens when women from the global South migrate. Or as anthropologist P. Sean Brotherton (2012: 53) writes:

The implementation of public health programs provided the [Cuban] state with quantifiable means [...] by which to measure success and bolster domestic and international recognition of the revolutionary achievements of the state. In the process, the government expended considerable capital - financial, social, political, and symbolic [...].

Here we delve behind those quantifiable means and various types of capital to grasp Cuban medical internationalism from a feminist perspective.

\section{Methods and procedures}

As explained in the previous section many studies already exist that outline the empirical effects of Cuban medical internationalism, ranging from revenue to the Cuban government to its effects on various health statistics. Our objective here is to add colour and context to those pre-existing studies through a non-empirical methodology (della Porta and Keating 2008). We base our data on 20 anonymous in-depth semi-structured interviews conducted with Cuban doctors (13 females and 7 males) who have participated, or are participating, in these medical missions. We used a set of 25 open-ended questions, which we asked interviewees to answer as they saw fit. The interviews typically lasted between 30 and 60 minutes, and they were either recorded or copious notes were taken in order to capture quotes as closely as possible to their original words. The 20 doctors we interviewed reflect Cuba's racial and regional diversity, as well as range in age, marital status, and the places where they complete(d) medical missions. For instance, interviewees were stationed in various Brazilian states, such as Rio Grande do Sul, São Paulo and Tocantins. Besides Brazil, our sample group also completed medical missions in countries such as Honduras, Venezuela and Ghana.

To account for a possible bias of the Cuban state, we interviewed both doctors who are currently participating in these missions and many who have participated and since immigrated to other countries and no longer have ties to the Cuban government. To our surprise, the responses of every participant appeared to correlate rather well, regardless of their location or status within or outside of a mission. The researchers did not experience any hesitancy from any of the doctors in participating, and most seemed to enjoy sharing their experiences. Contacts were all made through mutual acquaintances, where doctors who participated then suggested other doctors they knew. The interviews were conducted in Spanish or Portuguese, and the research project was reviewed and approved by the Research Ethics Committee of the researchers' home university.

After conducting the interviews, we systematically analysed our data, which entailed analysing not only spoken responses, but also meta-data responses, and both the researchers' and participants' positionality. By meta-data we mean Fujii's (2010: 232) definition of spoken and non-spoken responses that must be analysed beyond literal value, and can 
include rumours, silences, denials, evasions and so forth. By positionality we mean the importance of the researchers' and participants' personal experiences in the research process. Due to this we approached the interview process as a tabula rasa, seeking to gather data and then analyse it without 'looking for' specific elements and biasing out results (Bray 2008: 303). Although we are two men conducting feminist research with mainly female participants, we believe it is important for men to engage in feminist research because we bring new points of view to the conversation and can integrate the experiences of men into gendered reflections. As Ackerly (2008: 28) writes: 'Feminist inquiry is not reserved for women or even for those who identify themselves as feminists. It invites every scholar to revisit his or her epistemology and core conceptualizations throughout the research process.' The researchers strove to gain as much rapport as possible with participants through informal conversations and by sharing personal experiences of travel and work abroad in order to ease any worries and make them comfortable. As we analysed our results, we reflected on any possible shortcomings of our interviews, since we are two white, university-educated men, which creates an inherent power imbalance.

Furthermore, we acknowledge our participants represent an elite portion of Cuban society, considering they have been given the opportunity to travel abroad, earn foreign currency and come from an elite profession. Therefore, our results may not be applicable to the experiences of, say, rural Cuban farmers or urban industrial workers. In order to enhance our argument, we attempted to triangulate our findings, wherever possible, with either empirical data or the findings of previous scholars. Our research is not the end of a discussion, but rather the beginning of a conversation that invites self-reflection and asks many new research questions. We have striven to make our claims and findings as robust as possible by engaging in critical reflection on both researchers and participants, as well as dialogue with previous scholarship. To use Wedeen's (2010: 264) words, 'By navigating between concrete details and conceptual abstractions, we can refine and undermine, negate and create novel explanations about politics.'

\section{Feminism, Cuban civil society and international politics}

We structured our interviews to begin with less sensitive topics, such as cultural differences first impressions of their host country and the like, as recommended by Leech (2002: 666). From there, we moved onto more sensitive topics, such as their opinion about feminism, family relations and other personal topics. Early on, we noticed that the question, 'What do you think about feminism?' and variants of it were usually met with silence from participants, looks of confusion and blank stares. After being pressed a little or being asked to answer the question as they saw fit, interviewees gave a wide array of responses that expressed confusion with the term, or what could be categorized as sexist responses. For instance, Miranda, ${ }^{2}$ a Cuban doctor working in Brazil answered with a blank stare and silence, followed by:

Miranda: Wow, difficult question. [Pause.] What do you mean? 
Interviewer: What do you think about feminism? You can answer however you like.

Miranda: Well [Pause] I think [Pause] that there is a big effort to make laws for a lot of things that sometimes do not exist, or that the woman herself, I think, is at times responsible for, and made up (Miranda, interview by authors, 1 July 2017).

Or as another Cuban doctor in Brazil, Beatriz said:

Interviewer: Did you ever face any discrimination as a female doctor in Cuba?

Beatriz: Discrimination is not quite the word, I would say. Cuba is a sexist country, the world is sexist, I lived with that, but discrimination is not the word. It's more like being an object. It carries all of that feminism stuff I hate and don't want anything to do with, but for example, it was more like if a male and female [doctor] were working the night shift together then he would think, 'Well if I can feel you up as well, then good'! I would not say discrimination, but more like feeling like an object (Beatriz, interview by authors, 19 August 2017).

These meta-data responses of silence, confusion and blank stares tell us a lot about the status of feminism in post-Soviet Cuban civil society, specifically that despite official government rhetoric about addressing feminist concerns and working towards gender equality, drastic changes have not occurred, at least as could be discerned from our fieldwork. This is not to say that feminism and feminist actions are non-existent in post-revolutionary Cuba; but rather, as Lutjens (2002: 221-223) argues, there is a complex relationship between the modern Cuban state, its institutions and individual women. Or as Fernandes (2005: 440-443) claims, social progress in Cuba, when it comes to gender, has often been framed as legal and economic equality stemming from a feminine - not feminist - approach to political activism. Put differently, although $48.9 \%$ of the 612 delegates ${ }^{3}$ in Cuba's national assembly are women (Whitney 2013), this has not yet completely or naturally led to a radical restructuring of gender roles and social power throughout Cuban civil society (Luciak 2005; Kapcia 2008: 50-51; Gordy 2015). This line of reasoning is not meant to imply feminist 'thinking' and 'feelings' are absent in post-Soviet Cuban civil society, as Beatriz's claim, 'It's more like being an object,' reveals. Women in Cuban society may often lack the social organisation, movement and literal words to express their frustrations through a gendered prism; but this should not be read as a paucity of burgeoning feelings or consciousness in regard to gender-based oppression.

To extend our argument further, let us consider what Migdalis, who is completing a medical mission in Brazil, shared during her interview about her ex-husband:

Interviewer: What do you think about feminism?

Migdalis: [Silence] What do you mean? 
Interviewer: However you would like to answer the question.

Migdalis: Well I think in Cuba we talk more about machismo. I think it depends on the man and on his culture. For example [the man] saying I can't do housework, or if his wife is a nurse saying she can't work the nightshift or work at night, or he feels inferior if his wife makes more money. But I think that is not common anymore. Of course, it was more common in earlier generations [...]. My husband used to do the dishes, and if he got home first he would make dinner (Migdalis, interview by authors, 1 July 2017).

In the same way that Beatriz interpreted her personal experiences through objectification, Migdalis has made sense of sexism and gender-based inequality around her through the lens of machismo, culture, and historical setting. Her use of the word 'machismo' speaks back to the centrality of male figures within Cuban society (Chase 2015), so much so that she interprets feminism as a problem of men's actions against women instead of as a means for women's organisation and empowerment to redress grievances and transform social practices. Furthermore, her use of the word 'culture' is also telling of how feminism and gender inequality, like most other sensitive or troubling topics in Cuban society, are typically addressed indirectly and with euphemisms. As Lutjens (2002: 221) writes, 'In postrevolutionary Cuba, problems are often discussed with reference to cultural level, using the standards of consciousness to replace both color and class in explaining the progress and problems that Cubans see.'

During the course of our interviews, none of our respondents answered questions regarding feminism with post-colonial, queer or intersectionality-based underpinnings, which is not to suggest these types of reflections are absent in post-Soviet Cuba; but rather they have not yet entered mainstream feminist understandings in Cuba. All of our informants did answer in the affirmative when asked, 'Do you agree with equality between men and women?' Feminism and its theoretical foundations, of course, can be difficult for many people to grasp, and even more so to present coherently during an interview. What we observed from our interviews, though, are the intricate ways in which these women understand and decode their gendered experiences through euphemisms, elaborate translations and varying discourses of power. This is also reflective of Gordy's (2015) argument that 'ideology' in Cuba is a continuously negotiated system of power relations and struggles, in which individual subjectivities/subjects are in a constant state of debate against/ with official discourses and state intentions.

In other words, to our participants, these experiences and their personal reflections are not automatically problematic, as they probably never framed them through a feminist theoretical lens. For them, they are everyday experiences. Albeit coming from a very different research context, this is reminiscent of Fujii's (2010: 236) conclusion after conducting interviews in post-genocide Rwanda:

What these women's denials taught me was that informants do not experience violence in the same neat, analytic packages that we 
researchers use in our fieldwork. Rather, people experience, remember, and recount violence through the lens of their own victimization.

Violence, here, could be replaced with sexism, feminism, or discrimination. We are not trying to label any individual research participant as a 'good' or 'bad' feminist or pass judgment on them for expressing what we interpret as a sexist claim or attitude. On the other hand, we call attention to the complexity of studying these topics and categories, because the variable one is analysing is not necessarily identifiable by the research participant, which speaks back to Sabsay's (2016) claim about the problem of concept 'translation' within the social sciences. Moreover, it is us (the authors) with university-level educations who are identifying and 'labelling' the above examples as sexist in order to understand them within a greater feminist context. One could also posit that our participants were hesitant to identify as feminists in the presence of male interviewers, reflecting the negative semantic and social connotation feminism often carries.

Moreover, their mis-identification of feminism echoes the ways in which female Cuban doctors conceptualise their place within Cuban and international politics, despite the silences that exist surrounding feminist dialogues within Cuba. Since the early years of the revolution, the Federation of Cuban Women (Federación de Mujeres Cubanas, FMC) has fulfilled many roles within Cuban society: mediating women's issues between civil society and the state, articulating the state's official position regarding gender equality, and holding a monopoly on feminist dialogues (Lutjens 2002; Fernandes 2005). However, what we contend is that despite this official relegation of gender-based issues to a specific institution, individual Cuban women still struggle with these issues and social processes in more nuanced ways than are apparent at first glance, as they form their own subjectivities, and this by extension affects the inner workings of medical missions.

To exemplify this point, we reflect on what Ana Clara, a doctor completing a mission in Venezuela, expressed:

Interviewer: What are the differences you see between men and women in Venezuela and in Cuba?

Ana Clara: Well, women here [in Venezuela] govern the men. Here women are strong. Hysteria fits, in Cuba we see that among women. Here it's the men that come to the clinic with hysteria fits, who are $19,20,21,22$ years old because of their girlfriend.

Interviewer: And what do you think about that?

Ana Clara: Well you can imagine [rolls eyes and smiles] what would you say about that? (Ana Clara, interview by authors, 25 June 2017).

As the above example demonstrates, it is not only Cuban men who are capable of machismo or of expressing sexist thoughts and ideologies. Cuban women can also adopt culturally constructed narratives around gender roles and how men and women should act, and then repeat them, thus participating in sexist social structures that work towards their own oppression. Thus, examining the feminist consciousness and perceptions of Cuban women abroad also sheds light on relations of power within the international system, 
considering women from the global South can express gendered perspectives of superiority towards other women and men from the global South, whom they might view as 'inferior' through a gendered or racialised binary. Thus, Enloe's (2014: 40-47) analysis of women from the global North travelling to the colonies and being able to exert traditionally male qualities through travel can also be extended to global South women who participate in migratory patterns. International politics is not a one-way street whereby men exert power over women; it is more complex (Enloe 1996: 188). Gender binaries permeate both the domestic and international political arena, and when Cuban female and male doctors travel abroad they carry these with them. Their conceptions of feminism, which were inculcated in them through socialisation within Cuban civil society may also affect the ways they interpret and act within their host countries.

\section{Cuban medical internationalism and family structures}

After questions about feminism and the differences the interviewees could observe between men and women in their host countries and Cuba, the interviews gravitated towards questions centred on personal and family life. Many doctors who previously completed a medical mission in another country and were now on their second or third declared their marriage had ended because of their participation in these medical programmes abroad. As doctor Katia, who completed medical missions in Honduras and Venezuela, shared:

Interviewer: In what ways did your participation in these programs affect your family relations?

Katia: Well terribly because my children really felt my absence, my mother had to go live there [her home] because who was going to take care of them? And my mother has different habits and it deteriorated my marriage to the point that we divorced. I gained material things, but I lost emotional things (Katia, interview by authors, 7 August 2017).

Or as another doctor, Consuelo, who completed missions in Brazil and Nicaragua, explained:

Interviewer: Who took care of them [her three children]?

Consuelo: My family, my mom, my sister, my aunts, were who took turns caring for them. That was my case but there are many who didn't have anyone to leave their children with and left them with neighbours... I left because my children honestly didn't have panties or shoes. You understand?... What leads us to all of these places is the economy, because you abandon your children, your husband, men leave their wives and all of this has brought a series of difficulties for the Ministry of Public Health where the majority of marriages have 
separated, in other words, it destroys us socially (Consuelo, interview by authors, 28 July 2017).

What these responses reveal are the complex outcomes that participating in these missions creates for every Cuban doctor. On the one hand, they gain material and economic empowerment they would otherwise not have had access to on the island, while also taking on an immense interpersonal strain that affects not only them, but also encompasses their entire family. Following this line of reasoning, one can view Cuban medical internationalism from the point of view of the Cuban state or as a policy and remark on the impressive public health changes it creates, but as Brotherton (2012:15-16) argues this ignores the tremendous human costs that are mainly shouldered by the doctors themselves. Through our interviews, we were able to appreciate how these missions result in both positive and negative consequences for Cuban doctors and the host communities where they work, as well as their extended families and communities back in Cuba. The line between positive and negative, however, is often difficult to draw. These mixed outcomes for female doctors recall Gold's arguments about how, 'internationalism is an intricate part of [Cuban] revolutionary praxis', but with time the Cuban revolution and state have given space for individual pursuits and agency within the folds and discourses of the revolution (2015: 105, 129).

Although we could hypothesise numerous reasons for why so many marriages among Cuban doctors who serve abroad end, it is probably a combination of many factors. Internet and phone services in Cuba are slow, expensive, and until recently inaccessible to most residents. The doctor abroad also becomes the main source of family income, meaning they could dictate how this income is distributed, which can alter the gender roles within a specific marriage, as a female doctor now decides how remittances should be spent. As Peggy Levitt (2001: 73) has shown through her fieldwork with Dominican immigrants to the USA, remittances can radically alter relations of power and strain family relations, as well as create resentment among recipients. In Brazil, for instance, Cuban doctors participating in the Mais Médicos program make about R $\$ 10513.00$ a month, ${ }^{4}$ of which they keep half while the rest goes to the Cuban state. Spouses left in Cuba could become resentful and not be able to relate to their significant other's exposure to new world views and material wealth. A reversal of gender roles whereby the female in the relationship becomes the 'alpha' partner could cause an incompatibility with the gendered ordering of Cuban society that culminates in divorce. This is one of the possible outcomes when men feel 'inferior', as Doctor Migdalis explained in the previous section, to their spouse in a society where machismo and patriarchy are deeply rooted (Núñez Sarmiento 2005, 2010). Our point here is not to intimate that Cuban doctors divorcing is a necessarily negative occurrence, considering divorce could also be interpreted as form of liberation, and that working abroad economically empowers Cuban female doctors. Instead, we propose that participation in these missions can affect the family arrangements and interpersonal relations of the individual participants, as doctor Carmen who participated in a medical mission in Venezuela explains: 
Interviewer: How did your time in Venezuela affect your relationship with your relatives back in Cuba?

Carmen: Well obviously we leave and unhinge ourselves from our families. I left two small children in Cuba, a daughter of nine and a son of five, with my husband. And in that moment it was the only option that one finds to help your family economically... this inarguably is a big weight if you don't have a well-balanced family. In my family we never had any dysfunction because we are a truly wellgeared family, well functioning. My husband, my children, my parents we lived in harmony and with good communication. But there are many families that fall into problems with conflicts (Carmen, interview by authors, 21 July 2017).

As doctors go abroad, their spouses, relatives, and even neighbours take on the responsibility of raising children and running households. For female doctors, this means shifting their share of household burdens to women, be it her mother, sister and/or neighbour, in order to have access to foreign capital. Viewed from a different angle, we have one woman from the global South shifting her gendered constraints onto another woman (or women) to enhance her personal agency, as similarly observed by Chin (1998). Certainly, this is not a completely asymmetric power relationship, as the doctor abroad then becomes socially indebted to the women who care for her family. The women in Cuba also benefit from the remittances and material goods that the doctor abroad sends home. This is a phenomenon we see with many women from the global South who migrate for employment and alter power relations and familial organisation.

Furthermore, many of our interviewees also revealed the ways in which their participation abroad affected their children's emotional and educational development and left them psychologically scarred. Children felt resentment and left behind by parents who sought better opportunities and income through participation in these programmes. The access to foreign capital and improved living standards these missions bring do not come with impunity; on the contrary, they come at a price to children, marriages, and families. The participation of any doctor in a medical mission alters the life and agency of everyone around them. Or as another doctor, Gonzalo, who completed medical missions in Venezuela and Brazil, explains when reflecting on leaving his daughter behind with his now ex-wife:

Interviewer: In what ways did your time abroad affect your family relations?

Gonzalo: Of course it affects marriages, you know the separation for so many years, almost all of us spend 4, 5, 6 years away and the separation slowly deteriorates the relationship. And the kinds of things that occur inside of missions, which well, let's not even talk about that [laughs]. It affects us, not being there present for our children, to help them with their studies and guide them in life's matters. It 
affects the children (Gonzalo, interview by authors, 25 November 2017).

This statement shows how women and men have their marriages and families affected by participating in the missions differently, following the gendered nature of power dynamics in the international system. Gonzalo's affirmation about 'things that occur inside of missions' is a euphemism for extra-marital affairs between mission participants, or with members of their host communities. As historian Christine Hatzky (2015: 256) presents through her fieldwork with Cuban veterans of the Angolan Civil War, it was very common for Cubans to engage in an 'Angolan Marriage' to ease the loneliness and stress of separation from loved ones. As Hatzky (2015: 253) explains, the Angolan Marriages were often referred to indirectly or were difficult to get people to talk about during interviews. In our fieldwork, many male participants shared what could be called a 'Venezuelan Marriage' or 'Brazilian Marriage' whereby they had long-standing relationships with local women and some even fathered children. One of our participants is now married to his Brazilian significant other, after divorcing his first wife.

Our male interviewees admitted being away from home certainly affected them and their children and they felt sadness due to the separation, while remarking on how it must be even worse for women, considering women's important and 'different' bond with children. These assertions reflect a deeper gender inequality whereby women working abroad are expected to miss their family back home and want to return, while it is more socially acceptable for men to marry a local woman and not return. We did interview Cuban women who arrived in Brazil single and not already mothers and who then married Brazilian men and stayed. However, being a parent in Cuba or having a pre-existing marriage and then remarrying abroad seemed an almost exclusively male venture. Both men and women are able to participate in these foreign medical missions to enhance their agency and income, but even while abroad there are still different expectations for women. As our interview with Midgalis presents:

Interviewer: How does being here affect your relationships in Cuba? Midgalis: My parents are very proud to have a daughter abroad doing a mission, for them it's a sign of pride. They tell everyone who visits the house about it.

Interviewer: I understand, and did you ever face any judgment from any other Cuban women for leaving your son and coming here to Brazil?

Midgalis: No, no, I think most people understand the reasons why we choose to go abroad. Which are for better opportunities and to help our relatives. [Eyes begin to water] (Midgalis, interview by authors, 1 July 2017).

Although the experiences of every Cuban doctor we interviewed are unique, most expressed economic opportunity as their primary rationale for joining medical missions, while travelling and helping others as secondary motives. Access to economic opportunity 
and career advancement though are not free - they come at a personal price. For Midgalis, it was leaving her young son, whom she misses dearly, with her parents, as the tears that came to her eyes after being reminded of him would suggest. This is reminiscent of the sacrifices that both men and women who are employed internationally, or in internationally oriented sectors, must make to pursue their careers or advance their social and economic positions, and that affect everybody around them. International politics depends on individuals' labour in order to function, but these individuals bear different burdens depending on their gender and gender roles. Likewise, the participation of women in international politics and labour markets creates a heightened opportunity to disrupt and alter gender roles within their families, which may consequently reshape patriarchal arrangements, at least on the personal level.

\section{Relations of power and transformative experiences}

Another focus of our interview questions was attempting to gauge in what ways, if any, Cuban doctors affect and are affected by their host communities, and how their time abroad changes or transforms their world view. In order to obtain these insights, we asked our participants to detail their day-to-day activities, as well as memories that most stood out to them. From their responses we observed how stepping outside of their native political and social communities created, for women and men, opportunities for personal reflection on their society, profession and self they had not had before, as the following excerpt from our interview with Antonio, a young doctor working in Brazil exemplifies:

Interviewer: In what ways do you think that Cubans change Brazil, in other words, in what ways do you think that all of you affect the people with whom you interact?

Antonio: Of course, look let me give you an example that I often use with people when that topic comes up. Cuban doctors are made to be family doctors, to touch and interact with the patient. I remember that when I arrived at the clinic for the first time my chair and the patient's chair were on opposite sides of the desk. I went in and immediately changed them, I want the patient here by my side [points at himself] so I can touch them and feel closer to them... From this alone the patient leaves the consultation feeling better, it's like a placebo, you know only Cuban doctors that are able to do that (Antonio, interview by authors, 19 August 2017).

Doctor Antonio re-arranging the chairs in his clinic might seem like a miniscule act; but in reality, he is physically tampering with decades or centuries of pre-established Brazilian ethics on doctor-patient relations. Secondly, his awareness of the potential power he holds over his patients, in the way he treats them, even in his ability to 'trick' them psychologically with a placebo affect demonstrates the inherent agency medical professionals hold in society. As Foucault (2003) argued, modern medical professionals are 
imbued with far-reaching agency and power over others through their ability to medicate, treat and even construct dialogues about what is and is not illness. This power combined with the identity generally created around Cuban doctors as benign, international agents of soft power results in a sizeable ability for them to affect their surrounding relations of power. The clinics, hospitals and societies to which these doctors are sent have a web of pre-established relations of power into which they become enmeshed. Cuban doctors, due to the combined social weight the identities of Cuban and doctor collectively carry, have considerable leverage to affect these power relations. That is not to say this is wholly positive or negative, but rather it is an outcome of this encounter.

Conversely, these power relations also affect Cuban doctors. Although they may arrive with pre-conceptualised notions of class, race, gender and relations within their profession, all of that is subject to influence with time in their host communities. For instance, many of the doctors sent to the countryside of the Brazilian state of Rio Grande do Sul, which was colonised by German and Italian immigrants in rather closed-off small villages, tended to remark on all of the cultural differences they noticed. Or as doctor Miranda (interview, 1 July 2017) also shared:

I had a patient from Bahia [north-eastern Brazilian state] that hooked up with a German girl and she got pregnant and well they had to leave and move to Bahia. People here are very racist. There's also a black doctor that works at our clinic and patients who don't know her name arrive and are afraid to ask for the black doctor. They would rather point to their skin before saying she's black, and I'm always like, 'You're looking for the black [emphatic intonation] doctor.'

This example reveals how time spent abroad challenges one to remark on cultural differences that would otherwise go unnoticed. Doctor Miranda is in a region of Brazil where she notices racialised acts considerably more than she noticed in Cuba. This opens her eyes to racist encounters she might not have identified before, or at least not with as much clarity. Upon returning to Cuba, she may now identify racist acts and racialised language in a more complete manner than before her time in Brazil, which in the long-run may cause her to radically (re)examine racial relations in her own country. The same can be said of other social structures, as interviewees shared numerous examples of the differences (positive and negative) they noticed between their host communities and Cuba.

For these individuals, their time abroad might be their first (or an expanded) chance to critically reflect on social relations back in Cuba because they have an 'other' against which to juxtapose their own cultural baggage and socialisation. This returns to Lutjens' (2002: 221) claim that in contemporary Cuban society class, race and other taboo topics are referenced to euphemistically as showing a lack of 'culture.' We did receive a lot of these types of responses as well, with allusions to 'lack of culture' on the part of individuals in the stories they shared. From their interpretation of these stories one can sense the beginning of a reflection on what a lack of culture actually implies, be it racism, machismo, etc. For our female research participants, and Cuban female doctors in these medical missions 
more generally, these encounters and reflections on foreign social systems and power relations might also lead towards a greater feminist or social consciousness.

Aside from altering and being altered by relations of power, living abroad creates a generally transformative experience for Cuban doctors, both female and male, in multiple other ways. First of all, they are given access to economic capital, which introduces them to liberal ideas and a market system not familiar to their relatives back in Cuba. Living and working within a capitalist system morphs the doctors' perception of income and labour, partially explaining why many choose to participate in multiple medical missions. The international reach of capital and the way it changes the lives of these doctors may present deeper effects if Cuba ever transitions towards a market economy, since many of its medical professionals would have a thorough understanding of that system from their time abroad. In addition to economic capital, participation in foreign medical missions gives Cuban doctors access to new experiences retold during their interviews: travel, learning a language, being resourceful, etc. These experiences not only provide memories, but also work towards increasing the self-confidence, independence and subjectivity of these doctors, as they imbue them with an internationalised form of Bourdieu's social capital they can employ for the rest of their lives both in Cuba and abroad (see Basaran and Olsson 2017).

For male doctors, these experiences might be 'expected' of their gender, but for women who find themselves outside of Cuba's rigid patriarchal society, these experiences have a deeper, more liberating, feeling. Female interviewees retold stories of crossing the border into Uruguay to shop while working in Brazil or taking trips to Lake Titicaca on their own while working in Bolivia. This is reminiscent of Okin's (1998) argument that there exists a dichotomy within political theory between the private and public spheres, and women and their experiences are typically relegated to the private and domestic arena. Cuban medical missions give female doctors liberating and gender-equalising encounters as they step into the public and political sphere and engage in experiences typically reserved for men: travel, adventure, participation in the international. Stated differently, 'equality between the sexes' here does not necessarily imply the experiences of the genders meeting at the middle; quite contrarily, what we observe here are the experiences of select women becoming closer to those of men. This is not to say Cuban civil society fails to provide women with empowering experiences within the public sphere, considering participation within the FMC, and other organisations, allows women to become stakeholders in political conversations centred on women's issues. Likewise, the Cuban revolution has a long history of providing women with opportunities to participate in public political projects and reshape their personal identities, as the Literary Campaign well demonstrates (Fagan 1969). What we deduced from our qualitative fieldwork, though, is that medical missions provide a distinct and internationalised path for Cuban women to step into political and public projects, which furthers their agency, subjectivity, and capital(s), in manifold ways.

Despite the mixture of positive and negative experiences these doctors have abroad and upon returning home, as we have detailed throughout the previous sections, we did not find any feelings or suggestions of victimisation among our interviewees. On the 
other hand, most of our participants remarked on how strong and self-assured they felt after participating in medical missions and overcoming the day-to-day obstacles of working abroad. Yamile (interview, 21 July 2017), a doctor who completed missions in both Venezuela and Bolivia, expressed it as follows:

After that I said, 'Well now I can travel anywhere'. Because in the end without ever having left Cuba before Cubans sometimes think we know everything and it's not like that. Then you leave Cuba and you realize you don't even know half, and when you leave you realize that on the outside there is an endless amount of different things, that alone marks one.

Contact with the international is transformative; but it is transformative for every individual in different ways. Or as Pereira Pintado (2005: 149) found during her fieldwork on the Cuban Diaspora in the USA, 'We Cubans succeed wherever we are. We are intelligent, educated, hardworking, scrappy, and always inventive.' Interviewees, despite having to separate themselves from their families, working in oftentimes hostile environments, and navigating new cultural spheres, managed to decipher their experiences and incorporate them into their psyche. Nevertheless, as we have described in this section only select women in Cuban society have access to these traditionally male experiences, which has secondary affects for them and their families. In short, medical missions present women with an additional, and internationalised, way of working within the field of high politics and action beyond those available on the island, while also positioning them at a distance from state, revolutionary and familial bonds.

\section{Final considerations}

In 2012, The New York Times published an article titled, 'Cuba may be the most feminist country in Latin America' (Lopez Torregrosa 2012), typical of the exaggerated binary constructed around feminism and women in Cuba as either a socialist utopia or dystopia. The purpose of this research article has been to unpack and critically explore the lived and quotidian experiences of both Cuban men and women to better understand the nexus between gender and politics on the Caribbean island and abroad. Specifically, the previous discussion sections analysed the routines and power relations of Cuban medical professionals living abroad and participating in numerous South-South co-operation missions through a gendered perspective. In our first discussion section, we outlined how numerous, plural and oftentimes contrasting subjectivities and feminisms shape, and are shaped through, individual experiences on these medical missions. Then, we explored the negative and positive effects that international employment has on the doctors' interpersonal relations as they gain access to economic opportunities, while simultaneously bearing strained family relations. Finally, our analysis turned towards the ways in which these internationalised experiences lead towards the (re)construction of self-images and open up (or expand) spaces for personal agency. 
Previous scholarly accounts of Cuban medical internationalism have largely ignored the ways in which gender can affect the daily and local implementation of these programmes, which employ the labour of thousands of Cuban women, while not directly addressing the unique issues they face both at home and abroad. Cuban medical internationalism, when interpreted through a critical lens, reflects the difficulty of using clear-cut pre-defined concepts in feminist methodologies. For instance, the terms 'feminist' or 'not feminist' lose their strength as classifications and labels in a context such as Cuban civil society, where subjectivities are so varied, and individuals occupy a place of constant dispute and deliberation vis-à-vis the state and its official discourses. The FMC, non-state sanctioned civil organising, international groups, individual female doctors and so forth are all part of a sizeable web of both explicit and implicit social debate about the role of women within Cuban society and international political projects. Cuban medical professionals are also representative of the millions of people who engage in global migration patterns each year, especially between global South countries. The results and phenomena we have delineated are ones which female soldiers, diplomats and business leaders from both the global North and South can relate to, but in different ways, considering the hierarchical configuration of global political processes. Our research study encompassed the lives of both women and men to describe how contact with the international simultaneously alters social relations and capital acquisition at various points throughout the international arena. These shifts, however, come in different forms for every Cuban doctor, depending on their gender, and between individual women as well, depending on race, class, marital status, and other factors. Thus, our case study is one more example that reaffirms the work of previous feminist and post-colonial scholars, who argue that we cannot think of 'women' - and certainly not global South women - as monolithic and singular entities; instead we must work towards fully grasping and demystifying the place of individuals and identities within international politics.

\section{Notes}

1 This refers to the existence of two currencies in Cuba: the Cuban Peso and the Peso Convertible Cubano (or CUC). Salaries are in the weaker currency, the Peso; while all imported and luxury products are in CUC. Tourism industry employees and Cubans who receive remittances have greater access to CUCs.

2 All of the participants' names have been altered to another name that is not similar to their original one in order to protect their identity. The authors have translated all of the responses from the original Spanish or Portuguese.

3 This figure is based on Cuba's last election in 2013, where only the Communist Party was allowed to put forth candidates. At the level of provincial assemblies, women now claim 50.5\% of seats. Although each seat only has one candidate slated for it, candidates must get at least $50 \%$ of the votes or the party chooses a new candidate (Whitney 2013).

4 This equals about USD 3 300.00, of which they will keep half, while a doctor in Cuba typically makes only about USD 40 to 60 a month (Waters 2017). 


\section{References}

Ackerly, Brooke. 2000. Political Theory and Feminist Social Criticism. Cambridge: Cambridge University Press.

2008. 'Feminist methodological reflection.' In Audie Klotz and Deepa Prakash (eds), Qualitative Methods in International Relations: A Pluralist Guide. New York: Palgrave Macmillan, pp. 28-42.

Baldez, Lisa. 2012. 'Gender.' In Peter Kingstone and Deborah Yashar (eds), Routledge Handbook of Latin American Politics. New York: Routledge, pp. 319-332.

Barnett, Michael and Raymond Duvall. 2005. 'Power in international politics.' International Organization 59 (1): 39-75.

Basaran, Tugba and Christian Olsson. 2017. 'Becoming international: On symbolic capital, conversion and privilege.' Millennium 46 (2): 96-118.

Blue, Sarah A. 2010. 'Cuban medical internationalism: Domestic and international impacts.' Journal of Latin American Geography 9 (1): 31-49.

Bray, Zoe. 2008. 'Ethnographic approaches.' In Donatella della Porta and Michael Keating (eds), Approaches and Methodologies in the Social Sciences: A Pluralistic Perspective. Cambridge: Cambridge University Press, pp. 296-315.

Brotherton, P Sean. 2012. Revolutionary Medicine: Health and the Body in Post-Soviet Cuba. Durham: Duke University Press.

Brouwer, Steve. 2011. Revolutionary Doctors: How Venezuela and Cuba Are Changing the World's Conception of Health Care. New York: Monthly Review Press.

Bustamante, Michael and Julia Sweig. 2008. 'Buena vista solidarity and the Axis of Aid: Cuban and Venezuelan public diplomacy.' The Annals of the American Academy of Political and Social Science 616: 223-256.

Chase, Michelle. 2015. Revolution Within the Revolution: Women and Gender Politics in Cuba, 19521962. Chapel Hill: University of North Carolina Press.

Chin, Christine B N. 1998. In Service and Servitude: Foreign Female Domestic Workers and the Malaysian Modernity Project. New York: Columbia University Press.

Della Porta, Donatella and Michael Keating (eds). 2008. Approaches and Methodologies in the Social Sciences: A Pluralistic Perspective. Cambridge: Cambridge University Press.

Enloe, Cynthia. 1993. The Morning After: Sexual Politics at the End of the Cold War. Berkeley: University of California Press.

1996. 'Margins, silences and bottom rungs: How to overcome the underestimation of power in the study of international relations.' In Steve Smith, Ken Booth and Marysia Zalewski (eds), International Theory: Positivism \& Beyond. Cambridge: Cambridge University Press, pp. 186-202.

2014. Bananas, Beaches and Bases: Making Feminist Sense of International Politics. 2nd ed. Berkeley: University of California Press.

Fagan, Richard R. 1969. The Transformation of Political Culture in Cuba. Palo Alto: Stanford University Press.

Feinsilver, Julie M. 1989. 'Cuba as a “world medical power”: The politics of symbolism.' Latin American Research Review 24 (2): 1-34. 
2008. 'Cuban medical diplomacy'. In Mauricio Font (ed), A Changing Cuba in Changing World. New York: Bildner, pp. 273-286.

2010. 'Fifty years of Cuba's medical diplomacy: From idealism to pragmatism.' Cuban Studies 41: 85-104.

Fernandes, Sujatha. 2003. 'Fear of a black nation: Local rappers, transnational crossings, and state power in contemporary Cuba.' Anthropological Quarterly 76 (4): 757-608.

2005. 'Transnationalism and feminist activism in Cuba: The case of Magín.' Politics \& Gender 1 (3): 431-452.

Foucault, Michel. 2001. Power (The Essential Works of Foucault 1954-1984, Vol. 3). New York: The New Press.

2003. The Birth of the Clinic. London: Routledge.

Fujii, Lee Ann. 2010. 'Shades of truth and lies: Interpreting testimonies of war and violence.' Journal of Peace Research 47 (2): 231-241.

Gentry, Carol and Laura Sjoberg. 2015. Beyond Mothers, Monsters, and Whores: Thinking About Women's Violence in Global Politics. London: Zed Books.

Gleijeses, Piero. 2002. Conflicting Missions: Havana, Washington, and Africa, 1959-1976. Chapel Hill: University of North Carolina Press.

Gold, Marina. 2015. People and the State in Socialist Cuba: Ideas and Practices of Revolution. New York: Palgrave MacMillan.

Gordy, Katherine. 2015. Living Ideology in Cuba: Socialism in Principle and Practice. Ann Arbor: University of Michigan Press.

Hamilton, Carrie. 2012. Sexual Revolutions in Cuba: Passion, Politics, and Memory. Chapel Hill: University of North Carolina Press.

Hatzky, Christine. 2015. Cubans in Angola: South-South Cooperation and Transfer of Knowledge, 1976-1991. Madison: University of Wisconsin Press.

Hearn, Adrian. 2008. Cuba: Religion, Social Capital, and Development. Durham: Duke University Press.

Jerónimo Kersh, Daliany. 2017 'Women's small-scale, home-based informal employment during Cuba's Special Period.' Latin American Perspectives 45 (1): 175-194.

Johnson III, Ollie A. 2012. 'Race, politics, and Afro-Latin Americans.' In Peter Kingstone and Deborah Yashar (eds), Routledge Handbook of Latin American Politics. New York: Routledge, pp. 302-318.

Kapcia, Antoni. 2008. Cuba in Revolution: A History Since the Fifties. London: Reaktion Books.

Kirk, John M. 2009. 'Cuban medical internationalism and its role in Cuban foreign policy.' Diplomacy \& Statecraft 20 (2): 275-290.

Kirk, John M, Emily J Kirk and Chris Walker. 2015. 'Mais Médicos: Cuba's medical internationalism programme in Brazil.' Journal of the Society for Latin American Studies 35 (4): 467-480.

Kirk, John M and H Michael Erisman. 2009. Cuban Medical Internationalism: Origins, Evolution, and Goals. New York: Palgrave MacMillan.

Leech, Beth L. 2002. 'Asking questions: Techniques for semistructured interviews.' Political Science and Politics 35 (4): 665-668. 
Levitt, Peggy. 2001. The Transnational Villagers. Berkeley: University of California Press.

Lopez Torregrosa, Luisita. 2012. 'Cuba may be the most feminist country in Latin America.' The New York Times [online], 1 May. At https://rendezvous.blogs.nytimes.com/2012/05/01/cuba-maybe-the-most-feminist- country-in-latin-america/ [Accessed on 7 December 2017].

Luciak, Ilja. 2005. 'Party and state in Cuba: Gender equality in political decision making.' Politics \& Gender 1 (2): 241-263.

Lutjens, Sheryl L. 2002. 'Reading between the lines: Women, the state, and rectification in Cuba.' In Jennifer Abbassi and Sheryl L Lutjens (eds), Rereading Women in Latin America and the Caribbean: The Political Economy of Gender. Lanham: Rowman and Littlefield, pp. 213-230.

MINSAP. 2016. Anuario Estadístico de Salud. At http://bvscuba.sld.cu/anuario-estadistico-de- cuba/ [Accessed on 22 December 2017].

Mohanty, Chandra. 1988. 'Under Western eyes: Feminist scholarship and colonial discourses.' Feminist Review 30: 61-88.

Molyneux, Maxine. 2001. Women's Movements in International Perspective: Latin America and Beyond. New York: Palgrave Macmillan.

Núñez Sarmiento, Marta. 2005. 'Changes in gender ideology among professional women and men in Cuba today.' Cleveland State Law Review 52 (1): 173-188.

2010. 'A "top-down"-“bottom-up" model: Four decades of women's employment and gender ideology in Cuba.' In Elizabeth Maier and Nathalie Lebon (eds), Women's Activism in Latin America and the Caribbean: Engendering Social Justice, Democratizing Citizenship. New York: Rutgers University Press, pp. 76-92.

Okin, Susan Moller. 1998. 'Gender, the public, and the private.' In Anne Phillips (ed), Feminism and Politics. Oxford: Oxford University Press, pp. 116-141.

Pereira Pintado, Ana Celia. 2005. 'Religion and Cuban identity in a transnational context.' Latin American Perspectives 32 (1): 147-173.

Piedalue, Amy and Susmita Rishi. 2017. 'Unsettling the South through postcolonial feminist theory'. Feminist Studies 43 (3): 548-570.

Sabsay, Leticia. 2016. The Political Imaginary of Sexual Freedom: Subjectivity and Power in the New Sexual Democratic Turn. London: Palgrave Macmillan.

Sawyer, Mark Q. 2006. Racial Politics in Post-Revolutionary Cuba. Cambridge: Cambridge University Press.

Stout, Noelle M. 2014. After Love: Queer Intimacy and Erotic Economies in Post-Soviet Cuba. Durham: Duke University Press.

Tickner, J Ann. 1992. Gender in International Relations: Feminist Perspectives on Achieving Global Security. New York: Columbia University Press.

2001. Gendering World Politics: Issues and Approaches in the Post Cold-War Era. New York: Columbia University Press.

UN. 2016. Demographic Yearbook 76. At https://unstats.un.org/unsd/demographic/products/dyb/ dyb2.htm [Accessed on 15 December 2017].

Vrasti, Wanda. 2008. 'The strange case of ethnography and international relations.' Millennium: Journal of International Studies 37 (2): 279-301. 
Waters, Rob. 2017. 'The Cuban Hustle: Doctors drive cabs and work abroad to make up for meager pay.' STAT [online], 8 February. At https://www.statnews.com/2017/02/08/cuba- doctors-meager-pay/ [Accessed on 27 December 2017].

Wedeen, Lisa. 2010. 'Reflections on ethnographic work in political science.' Annual Review of Political Science 13: 255-272.

Whitney Jr, W T. 2013. '90\% voter turnout in Cuban regional, national elections.' People's World [online], 13 February. At http://www.peoplesworld.org/article/90-voter-turnout-in-cuban-regional-national-elections/ [Accessed on 15 November 2017].

\section{Acknowledgements}

The authors would like to thank Silvia Ferabolli, Rosana Resende, M. Leann Brown, Kevin Funk, Julie Feinsilver, Laura Sjoberg and two anonymous reviewers for their comments and suggestions throughout the production of the paper. The authors would also like to thank all of our interviewees for their time and CAPES for its funding.

\section{About the authors}

José O. Pérez is a master's degree candidate in International Strategic Studies at the Federal University of Rio Grande do Sul (UFRGS), in Porto Alegre, Brazil. Pérez holds degrees in Political Science and Latin American Studies from the University of Florida (2014) and has completed J. William Fulbright English Teaching Assistantship Grants in Brazil (2015, 2016). He is also a researcher at the Laboratório de Estudos e Pesquisas Internacionais e de Fronteiras (LEPIF) and his current research focuses on analysing the discourses and politics surrounding the Mais Médicos programme, as well as Brazilian foreign policy, more broadly.

André Luiz Reis da Silva is Associate Professor of International Relations and Coordinator of the Graduate Programme in International Strategic Studies at the Federal University of Rio Grande do Sul (UFRGS), in Porto Alegre, Brazil. He holds a PhD in Political Science from UFRGS and is Editor-in-Chief of Conjuntura Austral: Journal of the Global South. Reis researches politics between global South countries, focusing on Brazilian foreign policy and emerging powers in Asia and Africa. He was a post-doctoral fellow at the School of Oriental and African Studies (SOAS), University of London (2013). Currently, he is conducting research on the foreign policy of the Dilma Rousseff government and is a Research Productivity Scholar at CNPq (level 2). 


\section{Internacionalismo Médico Cubano através de uma Perspectiva Feminista}

Resumo: Este artigo analisa o internacionalismo médico cubano através de lentes feministas nas Relações Internacionais. Nossos resultados são baseados em numerosas entrevistas em profundidade semiestruturadas e trabalho de campo conduzido com tanto mulheres como homens participantes destes programas. Os médicos que entrevistamos concluíram as missões médicas em países como: Brasil, Venezuela, Angola, Gana, entre outros. Argumentamos que examinando o internacionalismo médico Cubano a partir de uma perspectiva feminista das Relações Internacionais nos dá conhecimento sobre o status nuançado do feminismo na sociedade civil cubana, como o emprego internacional impacta as relações familiares de forma positiva e negativa e como o tempo gasto no exterior fornece experiências transformadoras. Este artigo procura contribuir para maiores conversas sobre poder, agência e gênero no Sul global.

Palavras-chave: internacionalismo médico cubano; teoria feminista; sul global; poder; relações internacionais.

Received on 22 January 2018, and approved for publication on 18 September 2018. 